\title{
Short communication: Tick-borne disease is associated with changes in feeding behavior in automatically fed weaned dairy calves
}

\author{
B. R. Oliveira Júnior, ${ }^{* 1}$ B. F. Silper, ${ }^{* 1}$ M. N. Ribas, $†$ F. S. Machado,ł J. A. M. Lima,ł L. F. L. Cavalcanti, $\dagger$ \\ and S. G. Coelho*2 \\ *Department of Animal Science, Escola de Veterinária, Universidade Federal de Minas Gerais (UFMG), Belo Horizonte, MG, 30123-970, Brazil \\ †Conselho Nacional de Desenvolvimento Científico e Tecnológico (CNPq), Bolsista do Programa Recursos Humanos em Áreas Estratégicas \\ (RHAE)-SEVA Engenharia, Projeto Intergado, Contagem, MG, 32280-300, Brazil \\ †Embrapa Dairy Cattle, Juiz de Fora, MG, 36038-330, Brazil
}

\begin{abstract}
Tick-borne disease is a hemolytic disease complex that causes extensive losses to the dairy industry in tropical regions. Its timely diagnosis is challenging and labor intensive. Our objective was to investigate whether tick-borne disease was associated with changes in ingestive behavior of weaned dairy calves. Weaned calves $(\mathrm{n}=35)$ enrolled at $108 \pm 8 \mathrm{~d}$ of age were group housed ( $\mathrm{n}=12,12$, and 11/group) for $4 \mathrm{wk}$ in the experimental pen, which had 12 electronic feed bins and 2 electronic water bins. Data were automatically collected at each feed or water bin visit via radio frequency identification ear tags. Water and total mixed ration were provided ad libitum. Calves were examined weekly for tick-borne disease detection. A disease bout was confirmed if packed cell volume was $\leq 25 \%$ at any exam. Diseased calves received antimicrobial and antipyretic treatment. Data were summarized by day within bin type (feed or water) as intake $(\mathrm{kg} / \mathrm{d}$; as-fed basis), frequency of visits (visits/d), and total duration of visits (min/d). Day of detection was set as d 0; a 9-d behavioral screening period for evaluation of behavioral changes was set according to $\mathrm{d} 0(\mathrm{~d}-4$ to +4$)$. A within-calf mean was calculated for the healthy period (HP; mean of all days between 2 consecutive negative exams) for each response variable. Data were analyzed as within-calf differences between HP and each day of the behavioral screening period. Tick-borne disease was detected in 12 calves; thus, only data referent to these animals were included in the analyses. Compared with $\mathrm{HP}$, daily feed intake was reduced on $\mathrm{d}-1,0$, and +1 , and daily frequency and total duration of feed bin visits were reduced from $\mathrm{d}-3$ to $\mathrm{d}+4$. Daily feed intake was reduced by $35 \%$ on $\mathrm{d}-1(3.5 \pm 0.4$ vs. $5.4 \pm$
\end{abstract}

Received February 22, 2018.

Accepted August 12, 2018.

${ }^{1}$ These authors contributed equally to this work.

${ }^{2}$ Corresponding author: sandragesteiracoelho@gmail.com
$0.5 \mathrm{~kg} / \mathrm{d}$ for HP), and daily frequency and duration of visits were reduced by $27 \%(56.3 \pm 7.8$ vs. $76.7 \pm$ 8.1 visits/d for HP) and $24 \%(27.0 \pm 3.8$ vs. $35.4 \pm$ $3.9 \mathrm{~min} / \mathrm{d}$ for HP) on $\mathrm{d}-3$, respectively. Daily water intake on d $0(9.1 \pm 1.4 \mathrm{~kg} / \mathrm{d})$ was lower than at HP $(12.9 \pm 1.6 \mathrm{~kg} / \mathrm{d})$, but other drinking behaviors were not different from healthy means during the screening period. Feeding behavior, but not drinking behavior, was different from HP means before detection at weekly exams. Therefore, feeding behavior could be further explored for the development of algorithms for tick-borne disease detection.

Key words: feeding behavior, intake, health, precision dairy farming

\section{Short Communication}

Tick-borne disease, a hemolytic disease complex caused by the rickettsia Anaplasma marginale and the protozoans Babesia bigemina and Babesia bovis (Bock et al., 2004; Kocan et al., 2010), is among the most common postweaning diseases and causes of mortality in Brazilian dairy herds. Using experimental inoculations, Bastos et al. (2010) reported death in $60 \%$ of the calves that showed clinical symptoms. Incidence risks from birth until $180 \mathrm{~d}$ of age were $49 \%$ in a pasturebased system with 1,600 lactating dairy cows (Moreira, 2017 ) and $58 \%$ in a semiconfined heifer-rearing system (Mendonça, 2015). The losses associated with morbidity and mortality have been estimated at approximately $\$ 875$ million in Latin America and $\$ 300$ million in the United States (Kocan et al., 2003). The high incidence of anaplasmosis and babesiosis observed in countries with a tropical climate and the disease's challenging diagnosis contribute to the extensive losses and hindering of productivity.

The tick Rhipicephalus (Boophilus) microplus is a vector of A. marginale, B. bigemina, and B. bovis (Connell, 1974). Anaplasma marginale can also be transmitted vertically (Potgieter and van Rensburg, 1987) or by me- 
chanical vectors (e.g., hematophagous flies and fomites; Losos, 1986). Colostrum feeding provides calves with passive immunity against tick-borne disease pathogens up to 8 wk of age (Potgieter and van Rensburg, 1987). In addition, morbidity associated with tick-borne disease is lower in young calves (Kocan et al., 2003); therefore, it is generally recommended to expose calves to controlled tick infestation and to tick-borne disease pathogens during the preweaning period, leading to development of active immunity (Kocan et al., 2003). A large study ( $\mathrm{n}=9,538$ calves) of incidence and risk factors for tick-borne disease in a Brazilian grazing system reported first tick-borne disease bout on average at 125 d of age (Moreira, 2017); this observation is consistent with the disease's pathogenesis and common postweaning practices that expose calves to outdoor group housing for the first time at approximately $90 \mathrm{~d}$ of age. The retrospective study by Moreira (2017) reported that calves that had been treated for tick-borne disease were 2 mo older at first calving than their healthy herd mates, evidencing the long-term effect of this disease.

On-farm tick-borne disease detection is labor intensive and based on visual observation and clinical examination of animals. Clinical signs include paleness of mucous membranes, increased heart and respiratory rates, pyrexia, weakness, lethargy, and anorexia (Kocan et al., 2010). It is known that peak anemia occurs $2 \mathrm{~d}$ after peak parasitemia and $1 \mathrm{~d}$ after peak rectal temperature and is simultaneous with peak clinical symptomatology (Coelho, 2007). These observations indicate that the disease has already caused extensive damage at the stage where clinical diagnosis is feasible. Therefore, alternatives that allow early detection of tick-borne disease could improve prognosis and diagnostic efficiency. Pyrexia results from central effects of proinflammatory cytokines (tumor necrosis factor- $\alpha$, IL- $1 \alpha$, IL- $1 \beta$, and IL-6) and prostaglandin $\mathrm{E}_{2}$, which also induce behavioral changes such as anorexia, adipsia, depression, and reduced social interactions, usually addressed as "sickness behavior" (Pecchi et al., 2009). Reduced feed intake is often an early sign of disease (Johnson, 2002) that can now be continuously monitored using precision dairy management technologies. For example, it has been reported that calves reduce milk intake at the day of respiratory disease diagnosis (Swartz et al., 2017) and that cows present reduced DMI in the first 2 wk of lactation before the diagnosis of metritis (Huzzey et al., 2007; Schirmann et al., 2016). Therefore, the objective of this experiment was to investigate the association between tick-borne disease and feeding and drinking behavior (total daily intake, frequency of visits, and total duration of visits) of weaned calves relative to weekly disease detection routine. Our hypothesis was that naturally infected calves would show altered feeding and drinking behavior within a 9-d behavioral screening period ( $4 \mathrm{~d}$ before, $4 \mathrm{~d}$ after, and at the day of detection) in comparison with within-animal healthy behavior.

All procedures performed in this study were approved by the Ethics Committee on Animal Use (CEUA, Universidade Federal de Minas Gerais, Belo Horizonte, Brazil, protocol 306/2013). Between September 2013 and January 2014, 35 clinically healthy crossbred heifer calves (Holstein-Gyr; 50-96\% Holstein composition) presenting packed cell volume $(\mathbf{P C V})>25 \%$ were randomly selected at a commercial dairy located in Minas Gerais, Brazil $\left(20.0^{\circ} \mathrm{E}, 44.7^{\circ} \mathrm{S}\right.$; mean daily minimum and maximum temperatures were 20 and $29^{\circ} \mathrm{C}$, respectively). After being weaned at $90 \pm 3 \mathrm{~d}$ of age, the calves were moved to the group pen at $100 \pm 3 \mathrm{~d}$ of age, where they were allowed to habituate for a minimum of $1 \mathrm{wk}$ before initiation of the experimental period, which lasted 4 wk after habituation ended. During the habituation period, the calves received $2 \mathrm{~kg}$ of preweaning calf starter and ad libitum TMR (same formulation as that used in the experimental period). No feeding and drinking behavior data were recorded during habituation. The calves were $108 \pm 8 \mathrm{~d}$ of age and weighed 107 $\pm 16 \mathrm{~kg}$ (mean $\pm \mathrm{SD})$ at the start of the experimental period.

Calves were allocated to 3 experimental groups $(\mathrm{n}=$ 12,12 , and 11 calves/group). Each group was housed in the experimental pen for a total of 4 wk of data collection and then replaced by the next group. The experimental pen consisted of a dirt-floored open pack area equipped with 12 electronic feed bins (AF 1000 Junior, Intergado Ltd., Contagem, Brazil) and 2 electronic water bins (WD 1000 Junior, Intergado Ltd.). Calves had unrestricted access to all feed and water bins. A radio frequency identification passive transponder tag (FDX-ISSO 11784/11785; Allflex, Joinville, Brazil) was placed in the calves' right ear for electronic identification at the feed and water bins. Further details of feed bins are shown in Supplemental Figures S1, S2, and S3 (https://doi.org/10.3168/jds.2018-14637).

During the experimental period, calves were fed a TMR ad libitum twice per day at 0830 and $1600 \mathrm{~h}$ comprising $60 \%$ corn silage, 10\% chopped sugar cane, and $30 \%$ concentrate mix. Total mixed ration samples were collected weekly, pooled into monthly samples, and analyzed according to AOAC International (1995) methods for DM, CP, and NDF contents; results were $40.7 \pm 2.5 \% \mathrm{DM}, 14.1 \pm 1.0 \% \mathrm{CP}$, and $55.8 \pm 3.7 \%$ NDF (DM basis).

Behavioral data were retrieved from the electronic monitoring system software (Intergado Ltd.), which has 
been validated for monitoring feeding and drinking behavior of calves (Oliveira et al., 2018). Every time a calf visited a bin, the following information was automatically recorded: calf number; bin number and type (feed or water); and date, time, and weight of the bin content at start and end of each visit. The software calculated intake per visit $(\mathrm{kg})$ as the difference in weight between the bin content at start and end of the visit. Similarly, visit duration was calculated as the difference in time between start and end times of the visit. The response variables were summarized within bin type (feed or water) by day as total frequency of visits (visits/d), total intake (as-fed basis; $\mathrm{kg} / \mathrm{d}$ ), and total duration of visits $(\mathrm{min} / \mathrm{d})$.

The health of all calves was assessed 1 wk before enrollment and weekly thereafter according to Diaz et al. (2001). The clinical examination included measurement of rectal temperature, evaluation of the color of mucous membranes (mouth, eyes, and vulva; $1=$ normal, $2=$ pale, $3=$ icteric $)$, and hydration degree $(1=$ hydrated, $2=$ moderate dehydration, $3=$ severe dehydration). A blood sample was taken weekly from a small ear vessel by puncture with a 27-gauge needle and collected into a heparin-treated capillary tube. Capillary tubes were spun at $14,490 \times g$ for 5 min using a microhematocrit centrifuge (Spin 1000, Micro Spin, São Paulo, Brazil). A microhematocrit reading card was used to determine PCV. A calf with a PVC $\leq 25 \%$ at any posthabituation exam was considered to be positive for tick-borne disease. Diseased calves were treated with enrofloxacin (Kinetomax, Bayer, São Paulo, Brazil; $7.5 \mathrm{mg} / \mathrm{kg}$ of BW, 2 i.m. doses $48 \mathrm{~h}$ apart), imidocarb dipropionate (Imizol, MSD Saúde Animal, São Paulo, Brazil; 1.2 $\mathrm{mg} / \mathrm{kg}$ of BW, s.c.), vitamin $\mathrm{B}_{12}$ (Monovin $\mathrm{B}_{12}$, Bravet, Rio de Janeiro, Brazil; $5 \mathrm{~mL} /$ calf, s.c.), and sodic dipyrone (D 500, Fort Dodge, Campinas, Brazil; $10 \mathrm{~mL} /$ calf, i.m.).

Tick-borne disease was detected in 12 calves; therefore, this was the final sample size included in the analyses. None of these 12 calves were detected with tick-borne disease more than once, and no other diseases were observed during the experimental period. The day of tick-borne disease detection was set as d 0 , and the behavioral screening period comprised $\mathrm{d}-4$ to +4 relative to the detection day. Days between 2 consecutive negative exams (PVC $>25 \%$ ) were considered healthy days. For each response variable, a mean of all healthy days was calculated for each calf and denominated healthy period (HP) mean. Each day of the behavioral screening period $\left(X_{i j}\right.$, where $X$ represents the response variable at the $i$ th day for the $j$ th calf) was compared with the HP mean $\left(\bar{X}_{j}\right.$, where $\bar{X}$ represents the mean of the response variable for the $j$ th calf at all healthy days). Due to missing behavioral data, the number of calves included in the analyses for each day of the screening period was $6,9,6,12,12,7,7,7$, and 4 for $\mathrm{d}-4$ to +4 , respectively.

A repeated-measures model was fitted using a linear mixed approach. The model consisted of period (screening vs. healthy), day of the behavioral screening period $(\mathrm{d}-4$ to +4$)$, and period $\times$ day interaction and included experimental group $(1,2$, or 3$)$ as fixed effect and calf as random effect. An autoregressive covariate structure was used to account for error dependence based on the criteria of yielding the lowest Akaike information criterion and Bayesian information criterion. Variables were examined for normality and homoscedasticity. Model goodness of fit was assessed by residual analysis and metrics such as root mean squared error of prediction and mean bias. Pairwise comparison of LSM was done using Tukey-Kramer's adjustment for $P$-values; results are presented as least squares means \pm standard error of the mean. Differences were considered significant at a probability of error type I $<0.05$. All statistical analyses were conducted in $\mathrm{R}$ environment (R Core Team, 2014) using nlme (Pinheiro et al., 2013) and predict means packages (Luo et al., 2018).

At the day of tick-borne disease detection (d 0 ), calves were $125 \pm 16 \mathrm{~d}$ old (mean $\pm \mathrm{SD}$ ) and weighed $119 \pm 19 \mathrm{~kg}$. Rectal temperature was $40.4 \pm 0.5^{\circ} \mathrm{C}$, and PCV was $21.7 \pm 3.7 \%$ on d 0. During HP, feed intake was $5.4 \pm 0.5 \mathrm{~kg} / \mathrm{d}(\mathrm{LSM} \pm \mathrm{SEM})$, and frequency and total duration of feed bin visits were $76.7 \pm 8.1$ visits $/ \mathrm{d}$ and $35.4 \pm 3.9 \mathrm{~min} / \mathrm{d}$, respectively. Compared with HP means, daily feed intake was lower on $\mathrm{d}-1,0$, and +1 , and frequency and total duration of feed bin visits were reduced from $\mathrm{d}-3$ to $\mathrm{d}+4$ (Figure 1). Daily feed intake was reduced by $1.9 \mathrm{~kg} / \mathrm{d}(-35 \%)$ on $\mathrm{d}-1$, and frequency of feed bin visits and total duration of feed bin visits were reduced by 20 visits/d $(-27 \%)$ and 8 $\min / \mathrm{d}(-24 \%)$, respectively, on $\mathrm{d}-3$ compared with HP means. Water intake and frequency and duration of water bin visits during HP were $12.9 \pm 1.6 \mathrm{~kg} / \mathrm{d}, 7.2$ \pm 0.8 visits $/ \mathrm{d}$, and $3.6 \pm 0.5 \mathrm{~min} / \mathrm{d}$, respectively. Daily water intake was reduced on d 0 by $3.8 \mathrm{~kg} / \mathrm{d}(-30 \%)$ when compared with HP means (Figure 1). Frequency and duration of water bin visits were not different from HP observations.

The behavioral differences in feed intake, duration, and frequency of visits to the feed bin relative to HP observed in advance of or concomitantly to tick-borne disease detection are in agreement with sickness behavior responses, which include depression, anorexia, and adipsia as part of a physiological response by the animal to cope with disease (Hart, 1988). Tick-borne disease is associated with hyperthermia (body tem- 

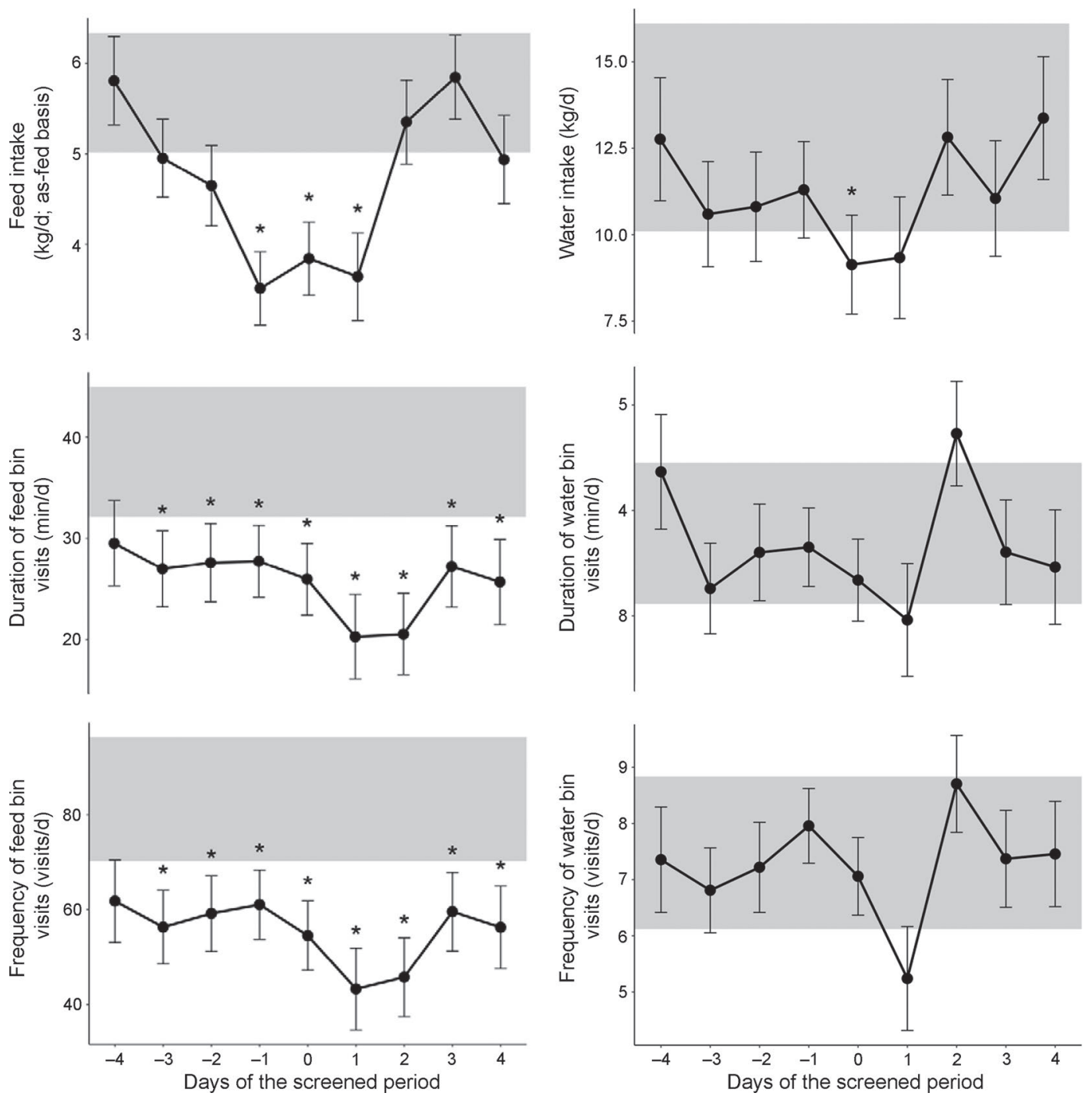

Figure 1. Feeding and drinking behavior $(\mathrm{LSM} \pm \mathrm{SEM})$ of weaned calves examined weekly for detection of tick-borne disease $(\mathrm{d} 0=\mathrm{detec}-$ tion day). The gray bands indicate the $95 \%$ confidence intervals for healthy period means. Asterisks indicate statistical difference $(P<0.05)$ between screening and healthy period means within day.

perature $\geq 40^{\circ} \mathrm{C}$ ), which is concomitant with increasing parasitemia (Kocan et al., 2003) and precedes peak anemia and peak clinical symptoms by $1 \mathrm{~d}$ (Coelho, 2007). Thus, the altered feeding behavior observed 3 to $1 \mathrm{~d}$ before disease detection, in comparison with the HP, could be a result of fever, which is known to be associated with reduced motivation for feeding and drinking (Hart, 1988). The observed feeding behavior patterns are in agreement with the occurrence of peak clinical symptoms, fever, anemia, and parasitemia over a $3-\mathrm{d}$ interval, although the convalescence period (time for PCV recovery) is approximately $30 \mathrm{~d}$ (Coelho, 2007).

Given that all 3 measurements were significantly different from HP means at least $1 \mathrm{~d}$ before detection via weekly examination routine, feeding behavior could potentially be applied toward early automated detection. Feeding behavior has been studied as an alternative for early diagnosis of respiratory disease in preweaned calves (Swartz et al., 2017) and for determination of overall morbidity in feedlot calves (Quimby et al., 2001). Behavioral variability within and between animals requires further evaluation with a greater number of observations for determination of detection thresholds.

Feeding behavior continued to be different from HP during the days that followed detection and treatment, likely due to the time needed for re-establishment of PCV, acid-base equilibrium, and hydration (Coelho, 2007). Future research should evaluate whether treat- 
ment following early automated detection would reduce the magnitude of altered behavior, which could improve prognosis, performance, and welfare of diseased calves.

By d +2 , feed intake reached normal levels (i.e., not different from HP means), likely in response to the antimicrobial and antipyretic treatment provided to sick calves on d 0. Precision tools could be applicable for comparing outcomes of different therapeutic strategies or detection timing as well as in determining calves that require follow-up treatment. Frequency and duration of feed bin visits, however, did not return to normal levels by $\mathrm{d}+4$. Although the experimental setting did not create a competitive feeding environment, disease could have affected the social structure within the pen and the calves' ability to compete for feed. The reduced frequency and duration of visits in association with normal feed intake indicates greater average intake per visit and feeding rate, as observed for smaller and subordinate calves in competitive situations (MillerCushon and DeVries, 2015).

Automated disease detection might facilitate large herd management by reducing labor, but the tools ought to be sensitive and specific enough for on-farm decision making (Rutten et al., 2013). Treating tickborne disease at the day of peak fever could benefit prognosis by placing treatment in advance of peak anemia. As observed for feeding behavior, reduced steps per day and increased lying bouts per day are observed $1 \mathrm{~d}$ before clinical diagnosis of respiratory disease in preweaned calves (Swartz et al., 2017). It is possible that additional behavioral measurements, such as lying behavior, physical activity, or body temperature, could be useful for tick-borne disease control.

Drinking behavior, however, did not present significant change ahead of detection. The reduction in water intake observed on d 0 could be associated with an increased thirst threshold due to fever (Hart, 1988) despite a metabolic state of greater water demand. Another possible confounding factor that could challenge the applicably of drinking behavior is the dependence between voluntary DMI and water intake (NRC, 2001). These results should, however, be examined with caution as the number of observations included in part of the screening period was limited. A reduced sample size can result in type II error; thus, further studies should be carried out to determine differences among healthy and sick behavior, especially regarding drinking behavior, which had a greater variability than feeding behavior.

In conclusion, feeding behavior of weaned calves affected by tick-borne disease was different from that observed for the same calves during HP. Thus, behavioral evaluations represent opportunities for automated detection of tick-borne disease with potential implica- tions on prognosis of this major cause of postweaning morbidity and mortality. In addition to resolution of the clinical case, early detection and treatment could minimize the period of reduced feed and water intake, which contribute to poor performance and welfare of diseased calves.

\section{ACKNOWLEDGMENTS}

The authors are grateful to Brejo Alegre (Itaúna, Minas Gerais, Brazil) dairy farm for their support and for allowing access to their facilities and calves. The authors also thank Intergado (Contagem, Brazil) for providing the electronic equipment for evaluation of feed and water intake.

\section{REFERENCES}

AOAC International. 1995. Official Methods of Analysis. 16th ed. AOAC International, Arlington, VA.

Bastos, C. V., L. M. F. Passos, E. J. Facury Filho, E. M. Rabelo, J. de la Fuente, and M. F. B. Ribeiro. 2010. Protection in the absence of exclusion between two Brazilian isolates of Anaplasma marginale in experimentally infected calves. Vet. J. 186:374-378.

Bock, R., L. Jackson, A. De Vos, and W. Jorgensen. 2004. Babesiosis in cattle. Parasitology 129(Suppl.):S247-S269.

Coelho, L. C. T. 2007. Anaplasmose bovina: Parâmetros clínicos e de patologia clínica em bezerros infectados experimentalmente. MS thesis. Universidade Federal de Minas Gerais, Belo Horizonte, Brazil.

Connell, M. 1974. Transmission of Anaplasma marginale by the cattle tick Boophilus microplus. J. Agric. Anim. Sci. 31:185-195.

Diaz, M. C., M. E. Van Amburgh, J. M. Smith, J. M. Kelsey, and L. Hutten. 2001. Composition of growth of Holstein calves fed milk replacer from birth to 105-kilogram body weight. J. Dairy Sci. 84:830-842.

Hart, B. L. 1988. Biological basis of the behavior of sick animals. Neurosci. Biobehav. Rev. 12:123-137.

Huzzey, J. M., D. M. Veira, D. M. Weary, and M. A. G. von Keyserlingk. 2007. Prepartum behavior and dry matter intake identify dairy cows at risk for metritis. J. Dairy Sci. 90:3220-3233.

Johnson, R. W. 2002. The concept of sickness behavior: A brief chronological account of four key discoveries. Vet. Immunol. Immunopathol. 87:443-450.

Kocan, K. M., J. Fuente, E. F. Blouin, J. F. Coetzee, and S. A. Ewing. 2010. The natural history of Anaplasma marginale. Vet. Parasitol. 167:95-107.

Kocan, K. M., J. Fuente, A. A. Guglielmone, and R. D. Meléndez. 2003. Antigens and alternatives for control of Anaplasma marginale infection in cattle. Clin. Microbiol. Rev. 16:698-712.

Losos, G. J. 1986. Rickettsial diseases: Anaplasmosis. Pages 742-795 in Infectious Tropical Diseases of Domestic Animals. Churchill Livingstone, New York, NY.

Luo, D., S. Ganesh, and J. Koolaar. 2018. Predictmeans: Calculate predicted means for linear models. $\mathrm{R}$ package version 1.0.1. Accessed Sep. 12, 2018. https://CRAN.R-project.org/package= predictmeans.

Mendonça, F. L. M. 2015. Utilização de isolados de Anaplasma marginale de baixa virulência em protocolos de imunização de bezerros: Análise dos efeitos pós-vacinais e proteção contra o desafio natural. MS thesis. Universidade Federal de Minas Gerais, Belo Horizonte, Brazil.

Miller-Cushon, E. K., and T. J. DeVries. 2015. Invited review: Development and expression of dairy calf feeding behavior. Can. J. Anim. Sci. 95:341-350. 
Moreira, G. H. F. A. 2017. Fatores de risco e impacto da tristeza parasitária bovina. PhD dissertation. Universidade Federal de Minas Gerais, Belo Horizonte, Brazil.

NRC. 2001. Nutrient Requirements of Dairy Cattle. 7th rev. ed. Natl. Acad. Press, Washington, DC.

Oliveira, B. R. Jr., M. N. Ribas, F. S. Machado, J. A. M. Lima, L. F. L. Cavalcanti, M. L. Chizzotti, and S. G. Coelho. 2018. Validation of a system for monitoring individual feeding and drinking behaviour and intake in young cattle. Animal 12:634-639.

Pecchi, E., M. Dallaporta, A. Jean, S. Thirion, and J. Troadec. 2009. Prostaglandins and sickness behavior: Old story, new insights. Physiol. Behav. 97:279-292.

Pinheiro, J., D. Bates, S. Debroy, D. Sarkar, and R Core Team. 2013 Nlme: Linear and nonlinear mixed effects models. $\mathrm{R}$ package version 3.1-110. Accessed Sep. 12, 2018. https://CRAN.R-project .org $/$ package $=$ nlme.

Potgieter, F. T., and L. van Rensburg. 1987. The persistence of colostral Anaplasma antibodies and incidence of in utero transmission of Anaplasma infections in calves under laboratory conditions. Onderstepoort J. Vet. Res. 54:557-560.
Quimby, W. F., B. F. Sowell, and J. G. P. Owman. 2001. Application of feeding behaviour to predict morbidity of newly received calves in a commercial feedlot. Can. J. Anim. Sci. 81:315-320.

R Core Team. 2014. R: A Language and Environment for Statistical Computing. R Foundation for Statistical Computing, Vienna, Austria.

Rutten, C. J., A. G. J. Velthuis, W. Steeneveld, and H. Hogeveen. 2013. Invited review: Sensors to support health management on dairy farms. J. Dairy Sci. 96:1928-1952.

Schirmann, K., D. M. Weary, W. Heuwieser, N. Chapinal, R. L. A. Cerri, and M. A. G. Von Keyserlingk. 2016. Short communication: Rumination and feeding behaviors differ between healthy and sick dairy cows during the transition period. J. Dairy Sci. 99:9917-9924

Swartz, T. H., A. N. Findlay, and C. S. Petersson-Wolfe. 2017. Short communication: Automated detection of behavioral changes from respiratory disease in pre-weaned calves. J. Dairy Sci. 100:92739278 . 